\title{
Petroleum geochemistry and oil-oil correlation of the Fahliyan and Surmeh reservoirs in the Garangan and Chilingar oilfields, the Dezful embayment (Sw Iran)
}

\author{
Mohammad Reza Kamali • Afsaneh Abolghasemi • \\ Rahim Bagheri · Ali Kadkhodayi
}

Received: 2 August 2012/ Accepted: 8 December 2012/Published online: 16 January 2013

(C) The Author(s) 2013. This article is published with open access at Springerlink.com

\begin{abstract}
The Dezful embayment located in southwest of Iran is one of the most potential areas for exploration and development of hydrocarbon reservoirs in the world. There are several source rock units with different geological ages. In this research, the Fahliyan and Surmeh reservoirs from the Garangan and Chilingar Dezful oilfields were studied using geochemical techniques including gas chromatography and carbon and sulfur stable isotope measurements. Carbon preference index of both reservoir oils was around one, indicating mature oil samples. The collected oil from both the fields was paraffinic in nature. $\mathrm{Pr} / \mathrm{nC} 17$ and $\mathrm{Ph} /$ nC18 sand ratio and the plot of $\delta^{13} \mathrm{C}$ (arom) versus $\delta^{13} \mathrm{C}$ (sat), both indicated that a marine reducing environment prevailed during the deposition of their progenitor source rock. The organic matter deposited in this sediment is of kerogen type II (algal). Plot of stable carbon isotope values versus $\mathrm{Pr} / \mathrm{Ph}$ ratio indicates that both oils originated from
\end{abstract}

M. R. Kamali

Faculty of Research and Development for Upstream Petroleum Industry, Research Institute of Petroleum Industry (RIPI),

Tehran, Iran

e-mail: Kamalimr@ripi.ir

\section{A. Abolghasemi $(\bowtie)$}

Department of Geology, Science and Research Branch,

Islamic Azad University, Tehran, Iran

e-mail: afsaneh.abolghasemi@yahoo.com

R. Bagheri

Department of Geochemistry, Exploration Directorate,

Tehran, Iran

e-mail: rbagheri-teartashi62@gmail.com

A. Kadkhodayi

Department of Geology, The University of Tabriz, Tabriz, Iran e-mail: kadkhodaie-ali@tabrizu.ac.ir the same shaly limestone belonging to Mesozoic. The results of isotopic and geochemical studies show that a single source rock contributed to the oil family found in both fields.

Keywords Garangan - Chilingar - Gas chromatography · Carbon and Sulfur isotopes · Fahliyan and Surmeh formations

\section{Introduction}

The southwest of Iran constitutes one of the most prolific hydrocarbon producing habitats (Bordenave and Burwood 1990) with cumulative recoverable of 136 billion $\left(10^{11}\right)$ barrels of oils including recent discoveries in the Kushk and Hosseinieh fields of Khuzestan province and 940 trillion $\left(10^{12}\right)$ cubic feet of associated and non-associated gas (James and Wynd 1965). Although the geology of this area is well defined (Jackson et al. 1981; Furst 1990; Sepehr and Cosgrove 2004; Less 1940), considerable uncertainty exists as to the origin of these hydrocarbons.

This story of geochemical investigation in Iran goes back to the years 1932-1941, when Less (1940) fractionated some crude oil as well as bitumen in the Fars area. The first comprehensive geochemical project in Iran was conducted by Bordenave and Sahabi (1971), Bordenave and Nili (1973), Burwood (1978), and Alizadeh et al. (2006). It was conducted to determine the characters of source rock and extent of their distribution. They also correlated the oils with probable source rocks and with tectonics of the Fars, Khuzestan and Lurestan regions.

Bordenave and Burwood (1990) carried out the important and comprehensive research work on the distribution and maturation of oils in the Zagros basin using stable 
isotopes on oils from the Fahliyan and Surmeh reservoirs as well as the probable source rocks in the Dezful embayment.

The probable source rock (Sargelu Formation) in the Garangan and Chilingar oil field has been analyzed by the geochemical techniques.

Stable carbon $\left(\delta^{13} \mathrm{C}\right)$ and sulfur $\left(\delta^{34} \mathrm{~S}\right)$ isotopes are a very powerful tools for oil-oil correlation (Craig 1953; Orr 1986). For high sulfur oils, a stable sulfur isotope study is suggested (Hunt 1996). Carbon isotope ratio of whole oils is generally not used alone for correlation because of the narrow range of $\delta^{13} \mathrm{C}$ values for all oils, which are about $-15 \%$, ranging from -18 to $-33 \%$ (Motiei 1995). Consequently, for oil-oil correlation, in this study, oil fractions were used. In geochemical investigations, multiple tools are recommended. Thus, to achieve better and more reliable results, normal Alkane distribution, determined by gas chromatography, was supported by stable isotope results.

\section{Geological setting}

The Zagros fold-thrust belt lies on the northeastern margin of the Arabian plate. Like other fold-thrust belts, it shows an intensive shortening, close to the suture which becomes less intense toward the foreland. It is dominated by NW-SE trending folds and thrusts. The mountain belt has been divided into NW-SE trending structural zones (imbricated and simply folded Belt) parallel to the plate margin, separated by major fault zones such as the high Zagros and mountain front faults. The imbricate belt situated between the high Zagros and Zagros main reverse faults, and simply folded belt lies to the southwest of the high Zagros fault (Less 1940).
Fig. 1 Garangan and Chilingar oilfields in the Zagros FoldThrust-Belt [modified from Sepehr and Cosgrove (Less 1940)]

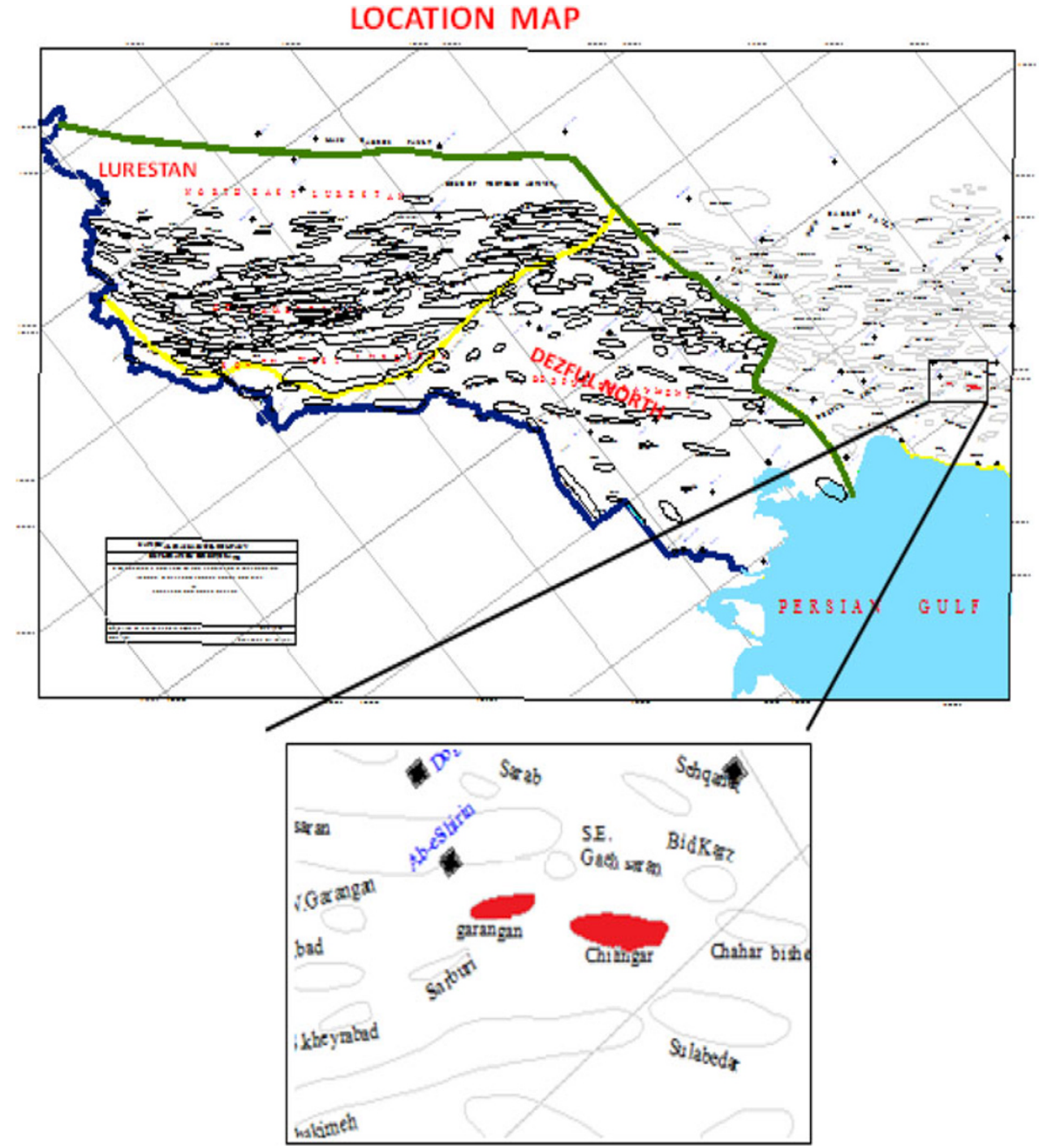


The Garangan and Chilingar oilfields are situated at the end of a simply folded zone, very close to the border of the folded zone (Southwest Iran) and unfolded zone (Arabian plate) (Fig. 1). From the middle of the Jurassic to the middle of the Cretaceous period, stratigraphy and structural geology in the Garangan and Chilingar areas were severely influenced by tectonic activities. Deposition of Sargelu Formation and Khami group took place from Middle Jurassic up to Cretaceous respectively (Shayesteh 2002). Khami group consists of Surmeh and Hith in Jurassic and Fahliyan, Gadvan and Dariyan in Cretaceous. The Batonian Sargelu formation consists of $115 \mathrm{~m}$ of gray and thin limestone. The Surmeh formation (Lower to Upper Jurassic is mainly composed of limestones sometimes, oolitic, with a few marly intervals $(936 \mathrm{~m})$. The Upper Jurassic Hith Formation (64 m thick) is dominated by anhydrite with intercalation of dolomitic limestones. The Fahliyan formation (Neocomian) which comprises slight gray limestones that are sometimes oolitic $(276 \mathrm{~m})$ and the Gadvan formation (Barremian), $27 \mathrm{~m}$ thick, is composed of porous and dolomitic limestones. The Aptian Dariyan formation consists of $57 \mathrm{~m}$ of gray to light brown marls and argillaceous limestones deposited in an oxic environment (Fig. 2).

\section{Methods}

For this study, four oil samples from producing wells of the Garangan and Chilingar oilfields were selected and analyzed using gas chromatography as well as stable isotopes of carbon and sulfur.

\section{Sample selection}

National Iranian Exploration Directorate (EXP) collected the oil samples for the present study from the selected wells all over the oilfield. Geological information, as well as chemical composition of the samples is given in Table 1 .

\section{Gas chromatography}

To perform Gas Chromatography (GC), asphaltene fraction from the sample was removed with n-hexane. The asphaltene free sample was injected into Gas Chromatography. Malten (Asphaltene-free oil) was injected in a heated port connected to a fused-silica cross-linked methyl silicone gum. The oven temperature was ramped from 50 to $320{ }^{\circ} \mathrm{C}$. The biomarker peaks were identified by Flame Ionization Detector (FID).

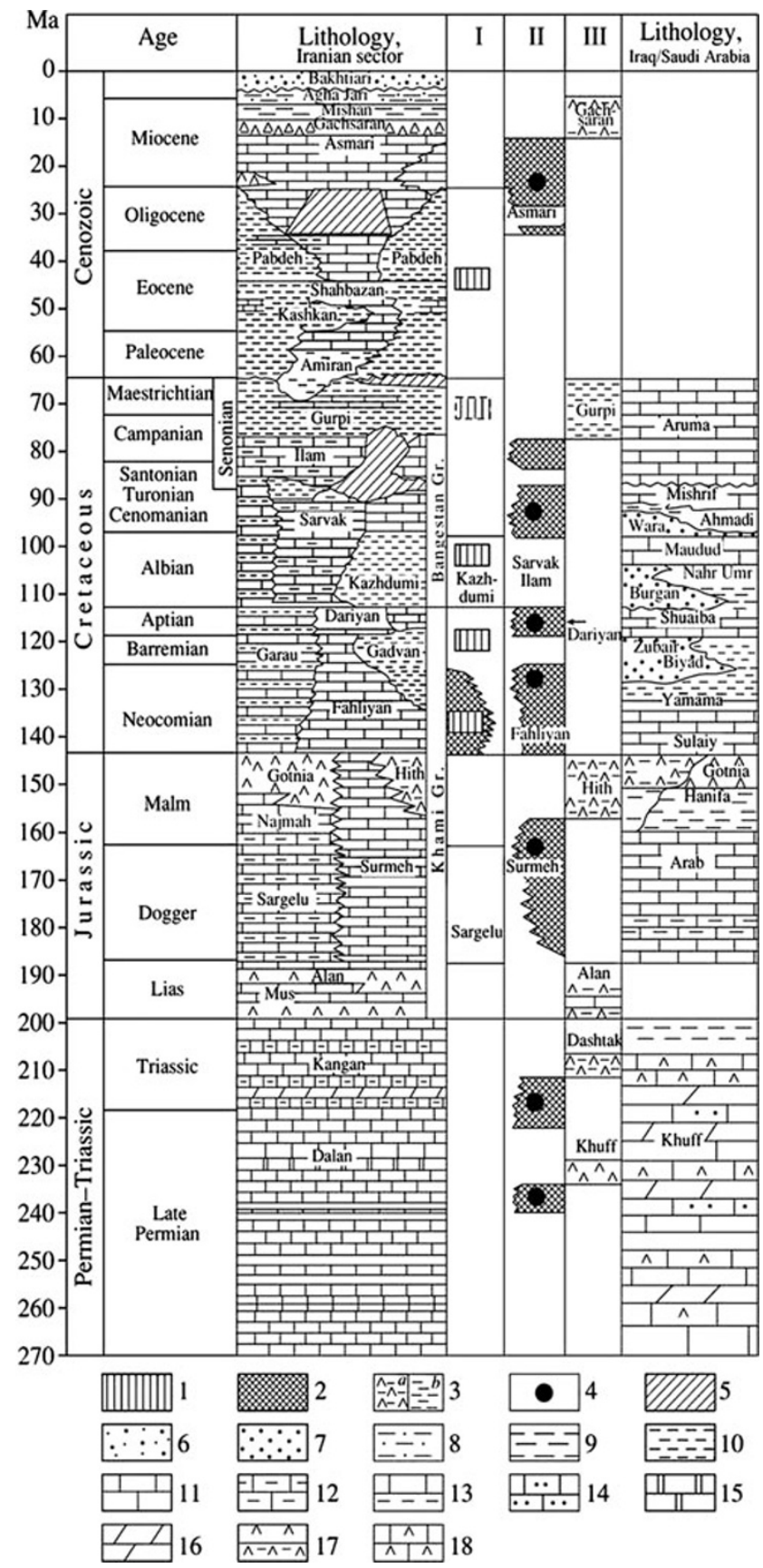

Fig. 2 Permian and Tertiary Stratigraphy of SW Iran (modified from Bordenave and Burwood, 1990). (I) Rocks capable of hydrocarbon generation; (II) rocks containing petroleum reservoirs; (III) rock units and horizons sealing petroleum reservoirs. (1) source rocks; (2) reservoir rocks; (3) impermeable rocks: salts $(a)$, clay $(b)$; (4) petroleum reservoirs; (5) washout zones: (6-18) rock types; (6) conglomerates andsiltstones; (7) sandstones; (8) alteration of sandstones and siltstones; (9) alteration of siltstones and clays; (10) clays and mudstones; (11) limestones; (12) clayey limestones; (13) alteration of limestones and clays; (14) sandy limestones; (15) dolomites; (16) marls; (17) gypsum and anhydrite; (18) alteration of limestones and anhydrites 
Table 1 Geochemical data and gross chemical composition of oils

\begin{tabular}{llllll}
\hline Well no. & Position & FM & Sat. (\%) & Aro. (\%) & Polar. (\%) \\
\hline Chilinga r3\# & Sw & Fahliyan & 67.54 & 31.98 & 0.48 \\
Garangan 4\# & Sw & Surmeh & 66.81 & 32.73 & 0.46 \\
Garangan 4\# & Sw & Fahliyan & 66.10 & 33.41 & 0.49 \\
Chilingar 3\# & Sw & Surmeh & 67.60 & 31.92 & 0.48
\end{tabular}

Isotope ratio mass spectrometry (IRMS)

\section{Sample preparation}

Total oil extracts were separated into their saturate and aromatic fractions by preparative silica gel chromatography. Hexane and toluene were used as elute solutions for saturate and aromatic separation, respectively.

Stable carbon isotope $\left(\delta^{13} \mathrm{C}\right)$ analysis

Stable carbon isotope ratios were determined on whole oil and oil fractions using EA-IRMS (Elemental Analyzer Isotope Ratio Mass Spectrometry) in Iso-Analytical laboratories. Carbon dioxide peaks separated by a packed column gas chromatography, held at an isothermal temperature of $110^{\circ} \mathrm{C}$, were entered as the ion source tube ionized and accelerated. Carbon isotopic composition (in per mill \%o) was reported relative to the Pee Dee Belemnite Standard (PDB) using the following equation (Ault and Jensen 1962):

$\delta^{13} \mathrm{C} \%=\left(R_{\text {sample }} / R_{\text {standard }}\right)-1 \times 1,000$

where $R$ is the ratio of ${ }^{13} \mathrm{C}-{ }^{12} \mathrm{C}$.
Stable sulfur isotope $\left(\delta^{34} S\right)$ analysis

Sulfur $\delta^{34} \mathrm{~S}$ analysis was undertaken by EA-IRMS. Sulfur dioxide is resolved on a packed GC-column at a temperature of $30^{\circ} \mathrm{C}$. Gas species of different masses are first separated in a magnetic field, then simultaneously measured on a Faraday cup universal collector array. Sulfur isotopic compositions (in per mill \%o) are reported relative to the standard Troilite Sulfur (FES) from the Canon Diablo meteorite using the following equation (Sofer 1988):

$\delta^{34} \mathrm{~S} \%=\left(R_{\text {sample }} / R_{\text {standard }}\right)-1 \times 1,000$

where $R$ is the ratio of ${ }^{34} \mathrm{~S}-{ }^{32} \mathrm{~S}$.

\section{Results and discussion}

Gas chromatography

In the studied samples, n-alkanes are high, indicating a high maturity level (Tissot and Welte 1984) for the Fahliyan and Surmeh reservoirs at Garangan and Chilingar oilfields. In order to represent compositional classification of the studied reservoirs, a ternary diagram of Tissot and Welte (1984) was used (Fig. 3). On the basis of whole oil minor cuts percentages, the studied oils show paraffinic composition with relatively higher maturity in both Fahliyan and Surmeh reservoir oils.

In gas chromatograms of all four oil samples, the Carbon Preference Index (CPI) is more than one, showing high maturity in both Fahliyan and Surmeh reservoir oils (Table 2).
Fig. 3 Ternary diagram showing paraffinic composition of Fahliyan and Surmeh crude oils from the Garangan and Chilingar fields

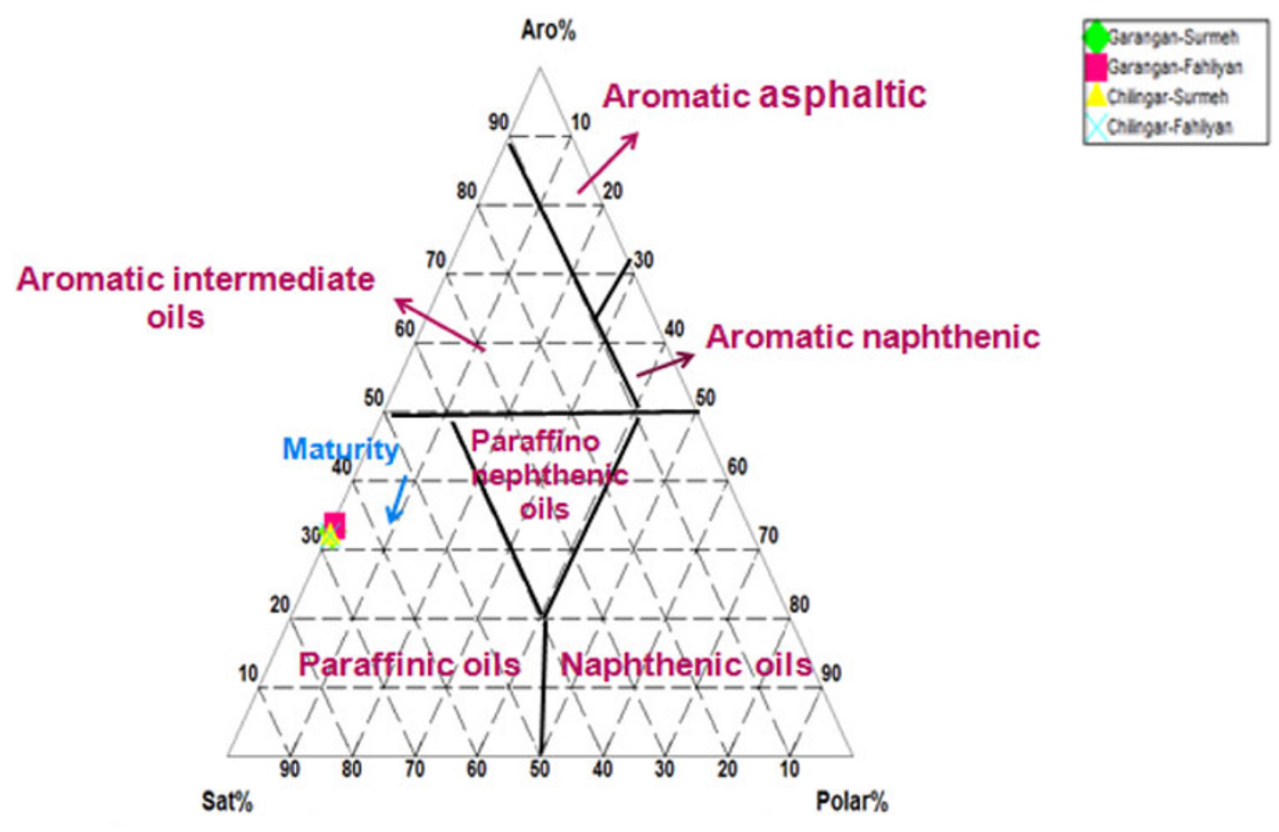


Table 2 Isotopic and Geochemical data of Fahliyan and Surmeh reservoir oils in Garangan and Chilingar oilfield

\begin{tabular}{lllllllllll}
\hline Well no. & FM & $\delta^{13} \mathrm{C}$ sat $(\%)$ & $\delta^{13} \mathrm{C}$ oil $(\%)$ & $\delta^{13} \mathrm{C}$ oil $(\%)$ & $\delta^{34} \mathrm{~S}$ oil $(\%$ ) & Pr/ph & $\operatorname{Pr} / \mathrm{n}-\mathrm{C} 17$ & $\mathrm{Ph} / \mathrm{n}-\mathrm{C} 18$ & $\mathrm{CPI}$ & $\mathrm{CV}$ \\
\hline Chilingar 3\# & Fahliyan & -26.2 & -25.5 & -26 & +2.4 & 0.91 & 0.35 & 0.45 & 1 & -2.025 \\
Chilingar 3\# & Surmeh & -26.5 & -25.7 & -26.2 & -0.64 & 0.88 & 0.35 & 0.45 & 1.04 & -1.71 \\
Garangan \#4 & Fahliyan & -26.7 & -25.2 & -26 & - & 0.88 & 0.36 & 0.45 & 1.07 & -1.871 \\
Garangan \#4 & Surmeh & -26.4 & -25.7 & -26.2 & - & 0.89 & 0.34 & 0.44 & 1.08 & -1.96 \\
\hline
\end{tabular}

Fig. 4 Pristane/n-C17 versus Phytane/n-C18 showing the marine source (type II kerogen with strongly reducing environment) for Fahliyan and Surmeh reservoir oils in Garangan and Chilingar oilfields [After Connan and Cassou (Kaufman et al. 1990)]
Fig. 5 Star diagram of normal alkane ratios in Fahliyan and Surmeh Reservoirs, showing significant similarity in all the oil samples from Garangan and Chilingar oilfields
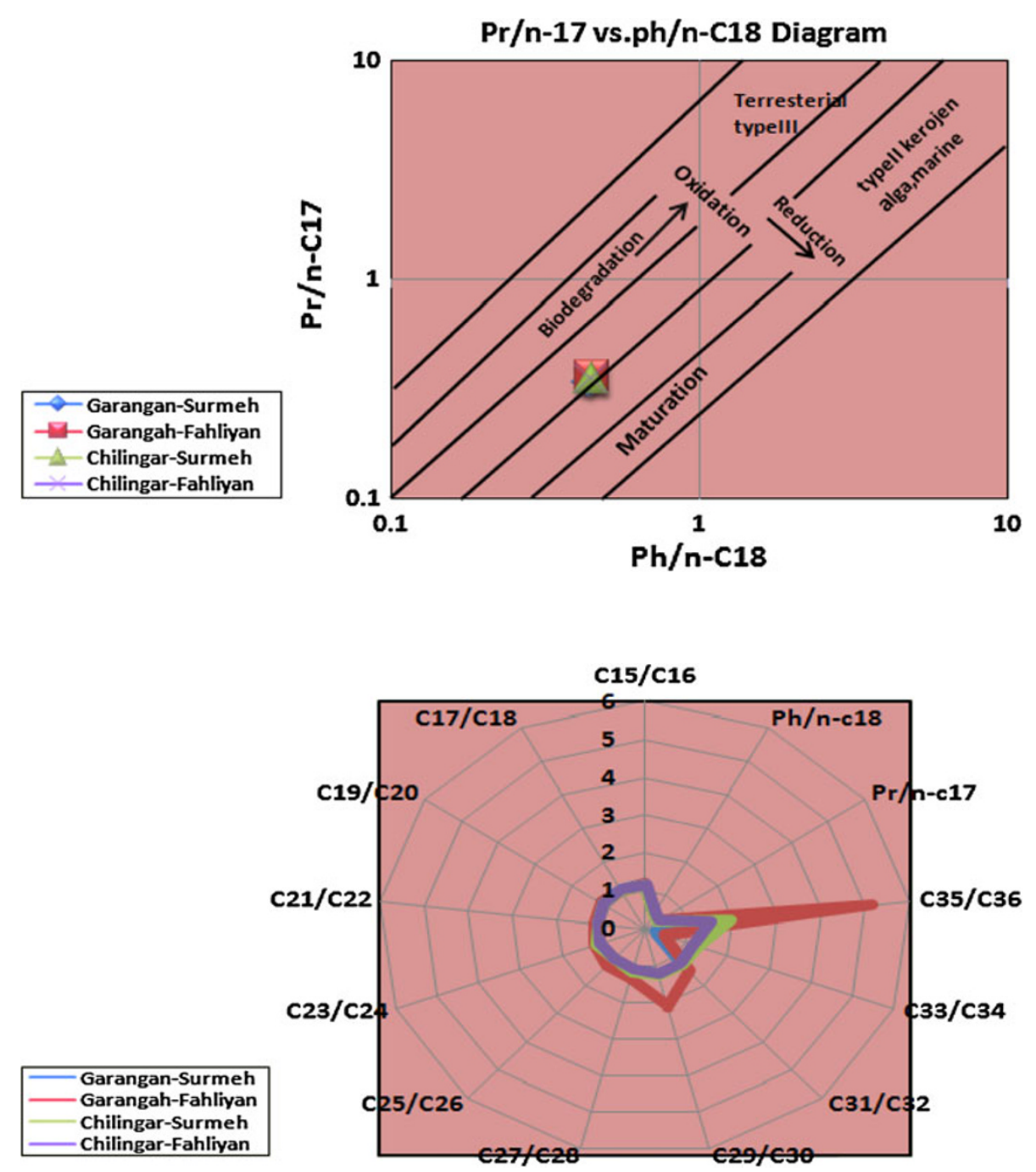

previous results. In all Fahliyan and Surmeh oil samples, the biodegradation phenomena are inactive since paraffinic is high in oil samples and also the isoprenoids (Pristane and Phytane) are quantitatively less than their adjacent normal alkanes (Fig. 4).

To correlate oil fingerprinting of both the reservoirs and to evaluate their origin, a sensitive star diagram was used (Sofer 1984). This correlation accurately shows their unique source from which they have been generated (Fig. 5). matter. Again, these data are in accordance with our reducing environment generally are from oils with a ratio of Pristane to Phytane $(\mathrm{Pr} / \mathrm{Ph})<2$ (Didyk et al. 1978; Waples 1985; Connan and Cassou 1980). For the studied oil samples, this ratio is $<1$ (Table 2). To determine the source of studied oils, a plot of $\mathrm{Pr} / \mathrm{nC} 17$ versus $\mathrm{Ph} / \mathrm{nC} 18$ was used (Kaufman et al. 1990).

The ratios demonstrate the algal source and kerogen type II with medium, high maturity for the original organic 
Fig. 6 A Sofer plot of $\delta^{13} \mathrm{C}$ values for the aromatic and saturate hydrocarbons in Fahliyan and Surmeh reservoirs. All $\delta^{13} \mathrm{C}$ values are in ppt (\%o) relative to $\mathrm{PBD}$

Fig.7 Canonical variable (CV) versus $\mathrm{Pr} / \mathrm{Ph}$

Fig. 8 Bivariate plot of $\delta^{13} \mathrm{C}$ ratio of oil versus $\mathrm{Pr} / \mathrm{Ph}$ ratio

The plot of $\delta^{13} \mathrm{C}$ values of aliphatic and aromatic hydrocarbon fractions of the oils (Chung et al. 1992) examined in this study show their sources have originated from a similar organic marine matter (Fig. 6). The difference between the two equations of terrigenous and marine oils was evaluated statistically and a statistical parameter, $\mathrm{CV}$ (the canonical variable),

$\mathrm{CV}=-2 / 53 \delta^{13} C_{\text {sat }}+2 / 22 \delta^{13} C_{\text {aro }}-11 / 65$

\section{Isotope carbon Aro VS.Isotope carbon Sat Diagram}
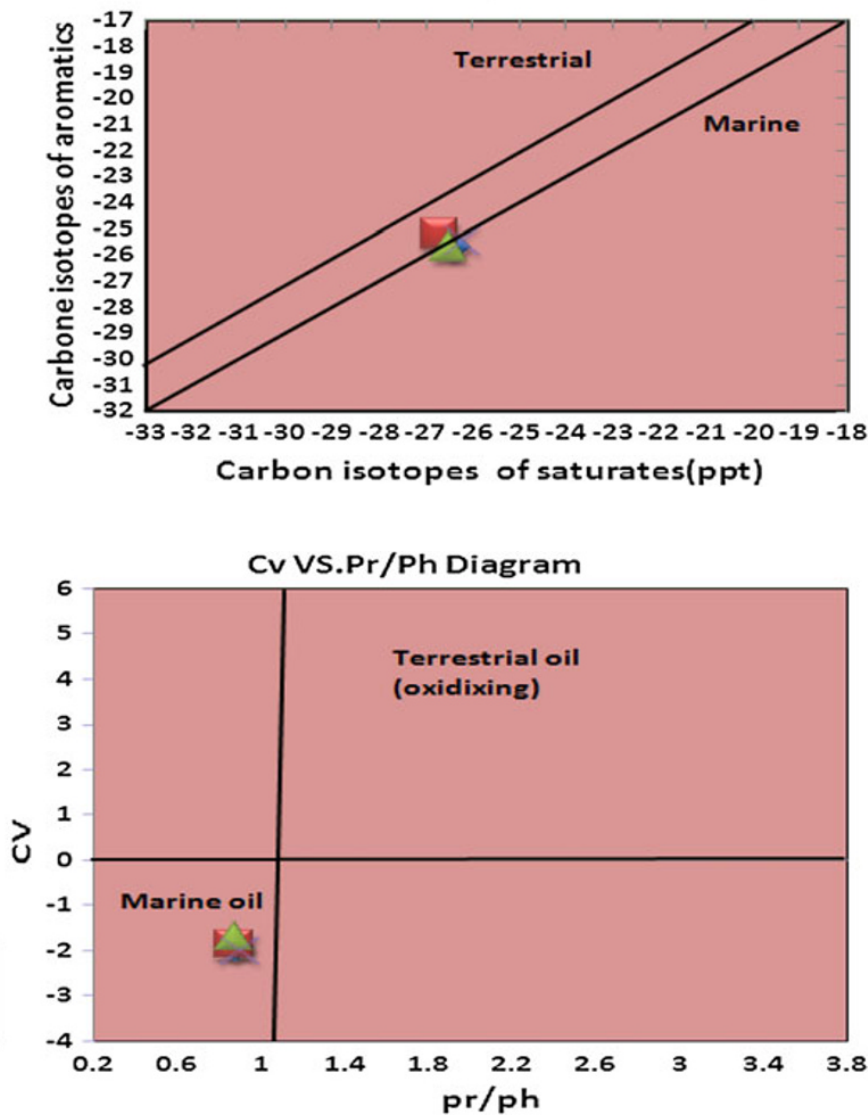

$\mathrm{Pr} / \mathrm{Ph}$ VS. Whole Oil Isotope Diagram

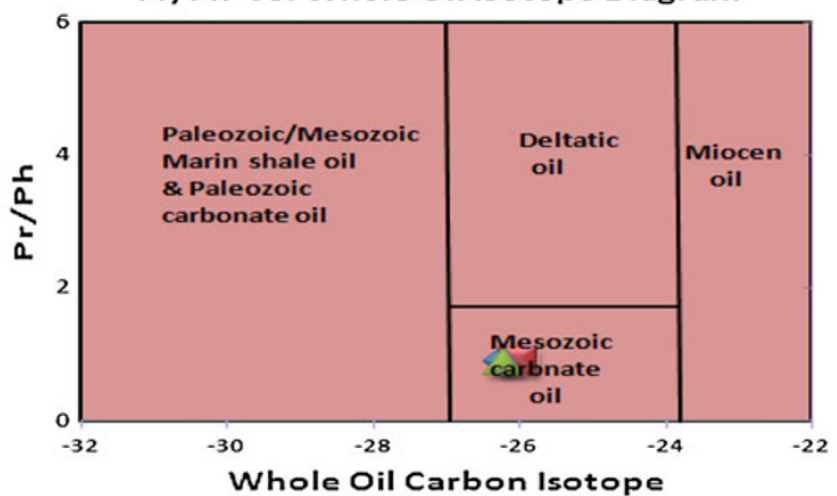

was used to distinguish between the marine and terrigenous oils. CV values larger than 0.47 indicate a predominantly terrigenous organic source for the oil, whereas $\mathrm{CV}$ values smaller than 0.47 indicate mostly a marine organic source (Chung et al. 1992). In this study, sulfur isotope $\left(\delta^{34} \mathrm{~S} \%\right.$ ) values were available for Chilingar well \#3 Fahliyan oil $=(+2.4 \%)$ and Surmeh oil $(-0.64 \%)$ respectively. Sulfur content in Surmeh reservoir in Chilingar oil field was reported $0.5 \%$ (MasoudShayesteh, personal communication). 
Fig. 9 Galimov curves for Fahliyan and Surmeh Reservoir oils

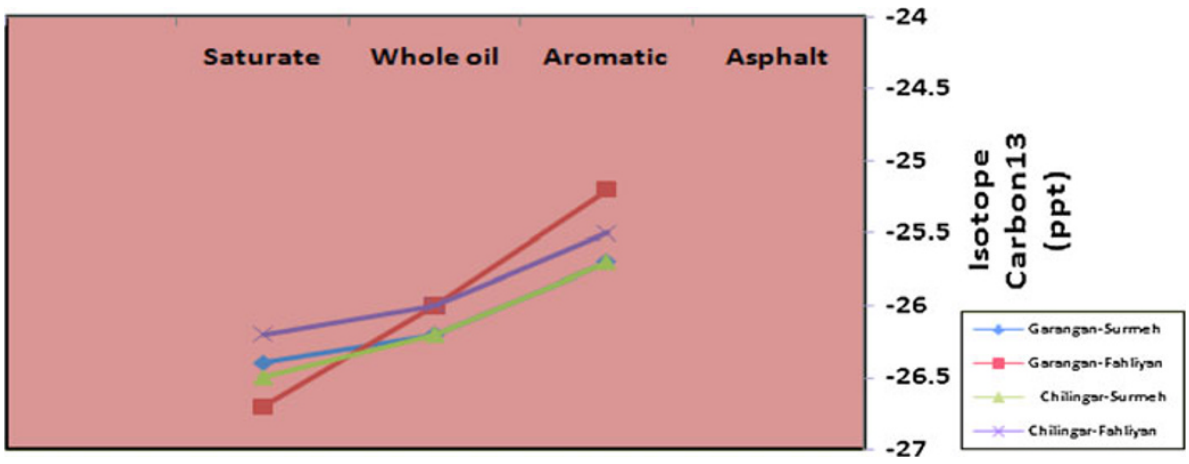

The ratio of $\mathrm{Pr} / \mathrm{Ph}$ can show a correlation with the isotopic composition of the oil, namely with the CV. The plot of the CV data versus the $\log$ of $\mathrm{Pr} / \mathrm{Ph}$ (Fig. 7) shows a positive trend between the two parameters: high $\mathrm{Pr} / \mathrm{Ph}$ ratios are associated with terrigenous oils having high values of $\mathrm{CV}$; low $\mathrm{Pr} / \mathrm{Ph}$ ratios are associated with marine oils along with low values of $\mathrm{CV}$, indicating that terrigenous sources are more commonly oxidizing in comparison with marine sources before they are incorporated into thick sedimentary sections (Chung et al. 1992).

Pristane/Phytane versus stable carbon isotope ratio of whole oil can be used to support genetic relationships among oils and infer depositional environments (Galimov 1973). The plot of $\mathrm{Pr} / \mathrm{Ph}$ versus whole oil stable carbon isotope ratio indicates Mesozoic argillaceous (Fig. 8). Interestingly, all samples from the Fahliyan and Surmeh reservoirs suggest a similar source rock.

The shapes and trends of stable carbon isotope type curves (Stahl 1978) can be used to identify the relationship between different crude oils. The curves of the studied saturate, whole oil, and aromatic fractions demonstrate only one oil family (Fig. 9).

The Fahliyan and Surmeh reservoir oils in the Garangan and Chilingar oilfields represent a similar argillaceous carbonate source rock, deposited under severe reducing environment. Geochemical parameters from the studied oils in both reservoirs show middle to high maturity and inactivity of biodegradation with high-paraffinic content. Also isotopic investigations in agreement with oil biomarkers confirm existence of a reducing environment for the deposition of progenitor source rock that sourced both reservoir oils. Stable carbon isotope in whole oil and saturate as well as aromatic fractions, conducted for the first time, demonstrated distinct oil (for both Fahliyan and Surmeh reservoirs) originated from a common source rock.

\section{Conclusion}

Detailed geochemical investigations on oil samples from Fahliyan and Surmeh formations indicated that these two show close similarities in terms of unique gas chromatogram and carbon isotope signatures. These two oils from Garangan and Chilingar oil fields are paraffinic and were originated from kerogen type II shaly limestone source rock deposited in an anoxic environment. This view is inferred from normal alkane distribution, $\mathrm{Pr} / \mathrm{n}-\mathrm{C} 17$ versus $\mathrm{Ph} / \mathrm{n}-\mathrm{C} 18$, and lower pristane to phytane ratio $(<1)$. Carbon Preference Index (CPI) was about 1 , suggesting that oils were generated from a mature source rock. Stable carbon isotope analysis conducted on saturate as well as aromatic fractions demonstrated distinct oil (for both Fahliyan and Surmeh reservoirs) originated from a common argillaceous carbonate source rock.

Acknowledgments The authors would like to thank sincerely the National Iranian Exploration Directorate (EXP), particularly the Research and Development department for financial support and Geochemistry department for technical management and providing samples and reservoir information.

Open Access This article is distributed under the terms of the Creative Commons Attribution License which permits any use, distribution, and reproduction in any medium, provided the original author(s) and the source are credited.

\section{References}

Alizadeh B, Adabi MH, Tezheh F (2006) Evaluation of hydrocarbon potential source rocks in Marun oilfield using Rock -Eval-6. J Sci Univ Tehran 32(3):267-274

Ault WU, Jensen ML (1962) Summary of sulfur isotopic standard. In: ML Jenson (ed) Biogeochemistry of sulfur isotopes. National Science Foundation Symposium Pro (16-29), Yale University, USA

Bordenave ML, Burwood R (1990) Source rock distribution and Maturation in the Zagros Orogenic Belt. Provenance of the Asmari and Bangestan reservoir oil accumulations. Org Geochem Y 16:369-387

Bordenave ML, Nili AR (1973) Geochemical project, review and appraisal of the Khuzestan province. Report 1194, Geological and Exploration Division, Iranian Oil Operating Companies, Iran

Bordenave ML, Sahabi F (1971) Geochemical project, appraisal of Lurestan. Report 1182, Geological and Exploration Division, Iranian Oil Operating Companies, Iran

Bordenave ML, Nili AR, Fozommayeh C (1971) Geochemical project appraisal of Fars province. Report 1181, Geological and Exploration Division, Iranian Oil Operating Companies, Iran 
Burwood R (1978) Oil Service Company of Iran, internal reports 2/1978 (Kuh-eBangestan), 3/1978 (Aghajari-140), 17/1978 (Gachsaran- 89), 22/1978 (Binak-5)

Chung HM, Rooney MA, Toon MB, Claypool GE (1992) Carbon isotope composition of marine crude oils. AAPG 76:1000-1007

Connan J, Cassou AM (1980) Properties of gases and petroleum liquids derived from terrestrial kerogen at various maturation levels. Geochim Cosmochim Acta 44:1-22

Craig H (1953) The Geochemistry of the Stable Carbon Isotopes. Geochim Cosmochim Acta 3:53-92

Didyk BM, Simoneit BR, Brassell SC, Eglinton G (1978) Organic geochemistry indicators of paleoenvironmental conditions of sedimentation. Nature 272:216-222

Furst M (1990) Strick-slip faults and diapirism of the southeastern Zagros Range. In: Proceeding of Intentional Symposium on diapirism with special Reference to Iran (15-182)

Galimov EM (1973) Carbon isotopes in oil-gas geology. Moscow: nedra. Trans, by National Aeronautics and Space Administration, Washington

Hunt JM (1996) Petroleum Geochemistry and Geology. Freeman and Company, San Francisco

Jackson JA, Fitch T, Mckenzie DP (1981) Basement faulting and focal depths of the larger earthquakes in the Zagros Mountains(Iran). Geophys J Roy Astron Soc 6:561-586

James GA, Wynd JG (1965) Stratigraphic nomenclature of Iranian oil consortium agreement area. AAPG 49:2182-2245

Kaufman RL, Ahmed AS, Elsinger RJ (1990) Gas chromatography as a development and production tool for fingerprinting oils from individual reservoirs: application in the Gulf of Mexico. In: D Schumacher, BF Perkins (eds) GulfCoast oils and gases: their characteristics, origin, distribution, and exploration and production significance. Proceedings of the ninth annual research conference GCSSEPM. Society of Economic Paleontologists and Mineralogists Foundation, pp 263-282

Less GM (1940) Geology of the oilfield belt of SW lran and Iraq. Geology Magazine

Motiei H (1995) Petroleum Geology of Zagros. In: A. Hushmandzadeh (ed) Treatise on the geology of Iran. Geological survey of Iran

Orr WL (1986) Kerogen/asphaltene/sulfur relationships in sulfurrich Monterey oils. Org Geochem 10:499-516

Powell TG, McKirdy DM (1973) The effect of source material, rock type and diagenesis on the n-alkane content of sediments. Geochim Cosmochim Acta 37:523-633

Sepehr M, Cosgrove JW (2004) Structural framework of the Zagros Fold-Thrust Belt Iran. Mar Pet Geol 21:829-843

Shayesteh M (2002) The causes of pollution of Asmari oil by H2S gas in Marun oilfield. Report 5207, NISOC, p 52

Sofer Z (1984) Stable carbon isotope composition of crude oils: application to source depositional environments and petroleum alteration. Am Assoc Pet Geol Bull 68:31-49

Sofer Z (1988) Biomarkers and carbon isotopes of oils in the Jurassic Smackover trend of the Gulf Coast States USA. Org Geochem 12:421-432

Stahl WJ (1978) Source rock-crude oil correlation by isotopic type curves Geochim. Cosmochim Acta 42:1573-1577

Tissot B, Welte DH (1984) Petroleum Formation and Occurrence, 2nd edn. Springer Verlag, Heidelberg

Waples DW (1985) Geochemistry in Petroleum Exploration Boston: International Human Resources Development Corporation, USA 